\title{
The Study of XML Functional Dependency and Multi-Valued Dependency and Inference Rules Set
}

\author{
Liu Xiyin ${ }^{1}$, Cao Lijun ${ }^{2}$ and Zhongping Zhang ${ }^{3}$ \\ ${ }^{1,2}$ Hebei Normal University of Science \& Technology, China \\ ${ }^{3}$ College of Information Science and Engineering Yanshan University, China \\ Email: ${ }^{1}$ misscao6666@163.com, ${ }^{2}$ liuxiyin2003@sina.com,zpzhang@ysu.edu.cn
}

\begin{abstract}
This paper discusses and defines XML functional dependency and XML multi-valued dependency, making the formal definition of XML functional dependency and XML multivalued dependency and further defines the XML-trivial functional dependency and multivalued dependency. It defines the logical implication, base closures and minimal dependence and gives the set of inference rules that effectiveness and completeness are proved when functional dependency and multi-valued dependency exist simultaneously.
\end{abstract}

Keywords: functional dependency; multi-valued dependency; key; inference rules

\section{Introduction}

In the wake of the range XML application being wider and wider, there search of XML constraints becomes one of the most important tasks. More and more data are stored permanently in the form of XML, XML date-dependency is a very important field of research, such as how to design XML database efficiently to avoid redundancy and update anomalies. Data dependency plays an important role in database design, data management, data security, data mining and other fields. Data dependency can express the semantic information between the data, and more importantly the purpose of it is to design the core part of good data patterns, also the basis of standardized design. With XML being introduced by $\mathrm{W} 3 \mathrm{C}$ as a standard for data exchange on the internet, but because of the limitations in the semantic relationship expression between the data, the study of it is becoming increasingly important. In this essay, related data-dependency theory systems from relational database are drawn, and the formal definition of XML functional dependency and XML multi-valued dependency is proposed, so is the inference rules based on XML functional dependency and XML multi-valued dependency.

\section{XML Mode}

XML plays an important role in the data on the internet, XML mode design has become a hot topic of research. XML mode is a language to describe a class of XML documents which related constraints. The constituent part of the mode include: data type, element part, text type, entity type and its notation. Through a general document vocabulary can explain the meaning, function and usage of each part, and the relationship of various components by the structure constraints. Currently there are numerous XML modes being widely used, such as XML-Data, XML Schema, DTD (document type definition) and etc., while DTD is favored by the researchers because of its good consistency, scalability, simple use, compatibility and other features as the application of XML schema. DTD schema can guarantee the document format is correct. By judging whether the XML document meets the DTD schema, the effectiveness of the document and the correctness of the element of the document and the use of properties is obviously knowable. Therefore, DTD schema of XML document is used the most frequently and maturely. 
Before XML functional dependency and multi-valued dependency formal definition given, an example should be presented.

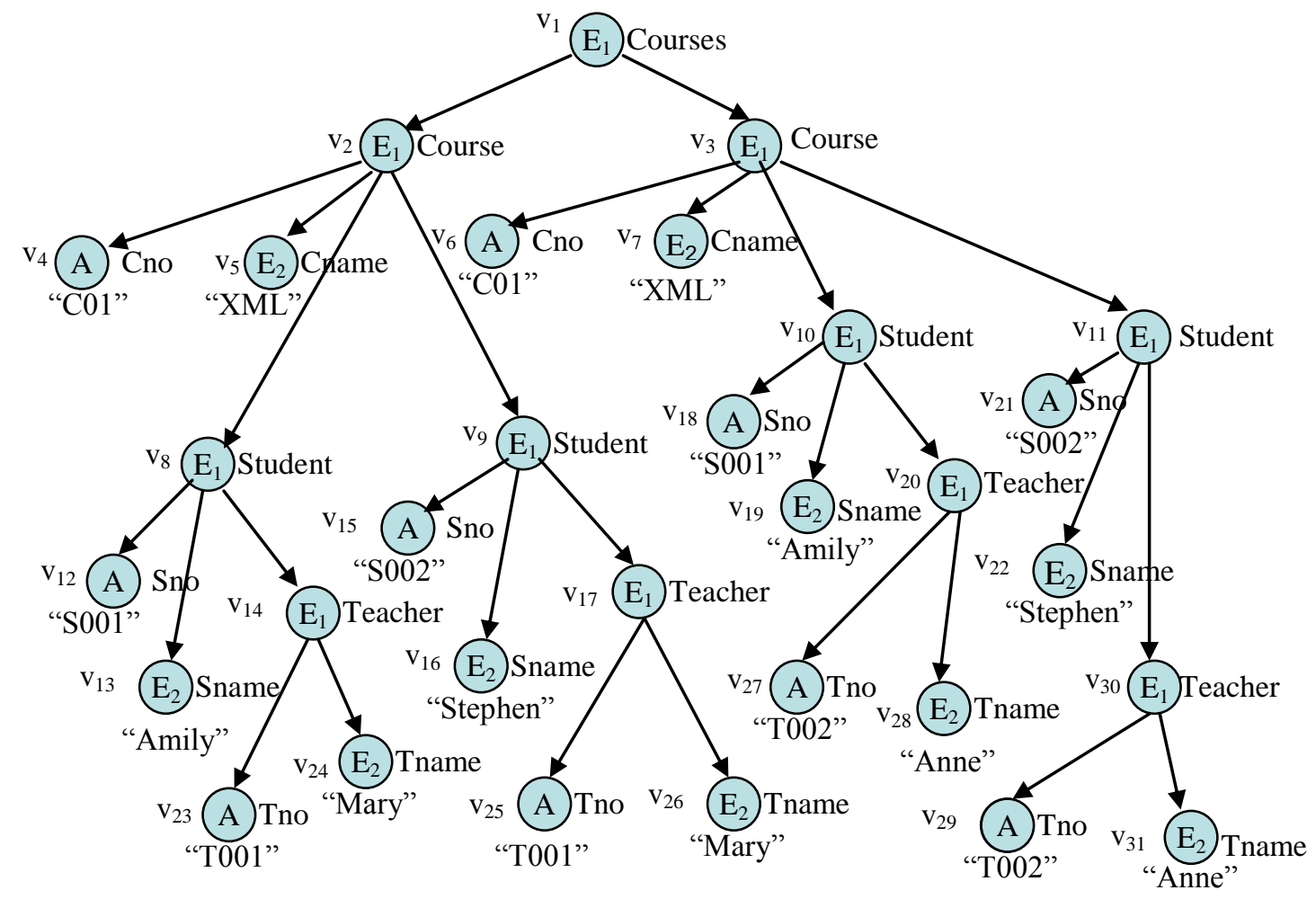

Figure 1. An XML DTD D1 which Meets Fully Documented Instances of T1

As can be seen from the document tree T1, the data dependency between the data of this XML document exists in the document tree structure. In the information of the course, its number is the unique identifier which determines its name accordingly. In the information of the student, the number of the student determines the name of the student, similarly, teachers' job number determines the name of the teacher, the modification of which bears similarities with the key concept of the relational database. In addition, there exist constraints: a course is taught by several teachers and a student can be guided by several teachers. These are more complex situations.

According to the description of the constraints, it can be seen that the data redundancy exists in the XML document. From the above example of the XML document tree, the duplication of the information of courses, students and teachers stored exists. Therefore the XML document is not a well-designed DTD document. In the relational schema, mentioning redundancy implies some dependencies existing between the data. XML document is similar to relational database, and the interdependency relation between the data in the XML document leads to the presence of the data redundancy. Reference relationship database represents the concept of the data dependency relation, which defined as functional dependency and multi-valued dependency in the XML document. Because relational model is complicate while the XML document is hierarchical, description of the functional dependency and multi-valued dependency in the XML document is different from the description of the functional dependency and multi-valued dependency in the relational model. XML document's hierarchy is described by the path expressions.

Example1: the relational table that expresses the case in Figure.1 is presented as follows: 
Table 1. A Case Based on Mode $\mathrm{R}$

\begin{tabular}{l|l|l|l|l|l}
\hline Cno & Cname & Sno & Sname & Tno & Tname \\
\hline C01 & XML & S001 & Amily & T001 & Mary \\
\hline C01 & XML & S002 & Stephen & T001 & Mary \\
\hline C01 & XML & S001 & Amily & T002 & Anne \\
\hline C01 & XML & S002 & Stephen & T002 & Anne \\
\hline
\end{tabular}

From the analysis of the Figure 1 it is knowable that the redundancy exists in the relational model R. Two students (S001 and S002) have selected Course C01, and there are two teachers (T001 and T002) valid. Within each course, all the students and teachers have their corresponding name. Namely, during students learning each course, the relevant information will be stored repeatedly according to the number of the teachers who teach this course.

The one-to-one relation among the properties in mode $\mathrm{R}$ can be represented by the functional dependency in the model $\mathrm{R}$ as follows: $\mathrm{Cno} \rightarrow$ Cname, Sno $\rightarrow$ Sname, Tno $\rightarrow$ Tname

In relational schema $R$, each course has a corresponding name, so does the student and teacher. This one-to-one relationship between properties is defined as functional dependency.

The one-to-one relation among the properties in mode $\mathrm{R}$ can be represented by the functional dependency in the model $\mathrm{R}$ as follows: $\mathrm{Cno} \rightarrow \rightarrow$ Sno $\mid$ Tno

In relational schema, there are many students selecting the same course, (one-to-many relationship), which is similar to the relation between teachers and courses (one-to-many), but there is no direct relationship between students and teachers. This one-to-many relationship among properties is defined as multi-valued dependency.

In Figure 1 the XML document instance tree is used to represent the relationship of chart 1 , it can be seen from the Figure 1 that instance tree T1 meets the existing of data redundancy in DTD D1,because in the XML document needs each course stored the information of students and teachers many times. If not, data inconsistencies and operational anomalies will arise.

(1) Data redundancy. If a course is taught by several teachers, this course is required to store repeatedly.

(2) Operational anomalies. Due to the presence of the redundancy in the data, all kinds of anomalies during operation will arise.

(a)Update anomalies. If the information of a course needs to be updated, accordingly, all the information about the relevant students who have selected the course needs to be updated. Otherwise the data will be inconsistent.

(b) Insertion anomalies. If a new teacher needs to be inserted in a course, his information needs to be inserted into the information files of all the students who have selected this course. Otherwise the data will be inconsistent.

(c) Deletion anomalies. If a teacher needs to be deleted, his information in the information files of all the students who have selected this course needs to be deleted. Otherwise the data will be inconsistent.

From the above analysis, it's know able that the DTD D1mode is clearly not ideal, since there exists a direct relation both between the courses and students, and the courses and teachers. However, due to the connection mentioned above, D1 nests the students and the teacher which bear no direct relation, resulting in data redundancy and abnormal operation 


\section{The Functional Dependence and the Multiple-Valued Dependence of XML}

\subsection{XML Functional Dependence}

It has relations among node sets in the document of XML. For instance, in the instance tree of Course.xml, each course has only one name, the same as teachers and students. This type of relation is named as the Functional Dependence of XML. Its formalized definition is as follow:

Definition 1(Functional Dependence of XML, XFD) DTD D given, $\mathrm{T}$ is a complete tree that satisfies $\mathrm{D}$. Provided that $\mathrm{P}=\left\{\mathrm{p}_{1}, \ldots, \mathrm{p}_{\mathrm{k}}\right\}$ and $\mathrm{Q}=\left\{\mathrm{q}_{1}, \ldots, \mathrm{q}_{\mathrm{m}}\right\}$ are the route sets of $\mathrm{D}$, $\mathrm{k} \geq 1, \mathrm{~m} \geq 1,(\mathrm{P} \cup \mathrm{Q}) \subset \mathrm{Paths}(\mathrm{D})$. To any two groups of the route instance in Paths $(\mathrm{Q}): \mathrm{V}=\left\{v_{1}^{1}, v_{2}^{1}\right.$. $\left.\ldots . v^{v_{1-1}^{1}} \cdot v_{l}^{1}, \ldots, v_{1}^{m} \cdot v_{2}^{m} \ldots . v_{n-1}^{m} \cdot v_{n}^{m}\right\}$ And $\mathrm{W}=\left\{w_{1}^{1} \cdot w_{2}^{1} \ldots{ }^{w_{l-1}^{1}} \cdot{ }^{w_{l}^{1}}, \ldots,{ }^{w_{1}^{m}} \cdot w_{2}^{m} \ldots . v_{n-1}^{m} \cdot w_{n}^{m}\right\}, \mathrm{n} \geq 1$, if the following conditions are satisfied, it is called that the Functional Dependence of $\mathrm{XML}\left(\mathrm{p}_{1}, \ldots, \mathrm{p}_{\mathrm{k}} \rightarrow \mathrm{q}_{1}, \ldots, \mathrm{q}_{\mathrm{m}}\right)$ is presented in the mode $\mathrm{D}$.

By definition 1 , route $p_{i} \cap q_{j}$ is a prefix of $q_{j}$. Hence, there is only one node that satisfies both in the set of $\left\{v_{1}^{i}, \ldots, v^{i}\right\}$ and the set of $\mathrm{N}\left(\mathrm{p}_{\mathrm{i}} \cap \mathrm{q}_{\mathrm{j}}\right)$. Namely, there is only one node included in xij. Similarly, there is only one node included in $\mathrm{y}_{\mathrm{ij}}$.

Case 2: In view of the presentation of Courses. Course. from the above analysis, it's obvious(knowable)that the DTD D1mode is clearly not ideal. since there exists a direct relation both between the course and students, and the course the teacher. however, due to the connection mentioned above, D1 nests the students and the teacher which bear no direct relation, resulting in data redundancy and abnormal operationCno $\rightarrow$ Courses. Course.Cname, $(\mathrm{k}=\mathrm{m}=1)$, the route living Cases of root $\mathrm{v}_{1} \cdot \mathrm{v}_{2} \cdot \mathrm{v}_{5}$ and $\mathrm{v}_{1} \cdot \mathrm{v}_{3} \cdot \mathrm{v}_{7}$ taken, and to make $v_{1}^{1} \cdot v_{2}^{1} \ldots$ $. v_{n-1}^{1} . v_{n}^{1}$ as $\mathrm{v}_{1} \cdot \mathrm{v}_{2} \cdot \mathrm{v}_{5}, w_{1}^{1} . w_{2}^{1} \ldots \ldots w_{n-1}^{1} \cdot w_{n}^{1} \mathrm{As} \mathrm{v}_{1} \cdot \mathrm{v}_{3} \cdot \mathrm{v}_{7}$, it is knowable that $\mathrm{x}_{11}=\mathrm{v}_{2}, \mathrm{y}_{11}=\mathrm{v}_{3}$.

Because last (Courses. Cno $) \notin \mathrm{E}_{1}, \operatorname{Nodes}\left(\mathrm{v}_{2}\right.$, Courses.Course. Cno $)=\mathrm{v}_{4}, \operatorname{Nodes}\left(\mathrm{v}_{3}\right.$, Courses. Course. Cno $)=$ $\mathrm{v}_{6}, \operatorname{val}\left(\mathrm{v}_{4}\right)=\operatorname{val}\left(\mathrm{v}_{6}\right)$. $\operatorname{val}\left(\right.$ Nodes $\left(\mathrm{v}_{2}\right.$, Courses.Course.Cno $) \cap \operatorname{val}\left(\mathrm{v}_{3}\right.$ Courses.Course.Cno $) \neq \varnothing$, then it Nanely $\operatorname{val}\left(\mathrm{v}_{5}\right)=\mathrm{val}\left(\mathrm{v}_{7}\right)$. Therefore,XFD; Courses.Course.Cno $\rightarrow$ Courses.Course.Cname is presented. In a similar way, Courses.Course.Student.Sno $\rightarrow$ Courses. Course. Student.Sname Courses.Course.Student.Teacher.Tno $\rightarrow$ Courses.Course.Student.Teacher. Tnameis presented as well.

Based on definition of the Functional dependence of XML, this paper will give a conception of the trivial functional dependence of XML.

Definition 2(trivial functional dependence of XML) Given DTD D, T is a complete tree that satisfies $\mathrm{D}$. Provided $\mathrm{P}=\left\{\mathrm{p}_{1}, \ldots, \mathrm{p}_{\mathrm{k}}\right\}$ and $\mathrm{Q}=\left\{\mathrm{q}_{1}, \ldots, \mathrm{q}_{\mathrm{m}}\right\}$ are the route sets of $\mathrm{D}, \mathrm{k} \geq 1, \mathrm{~m} \geq 1$. If $\mathrm{P} \subset \mathrm{Q}$, then functional dependence of $\mathrm{XML}\left(\mathrm{p}_{1}, \ldots, \mathrm{p}_{\mathrm{k}} \rightarrow \mathrm{q}_{1}, \ldots, \mathrm{q}_{\mathrm{m}}\right)$ is presented in mode $\mathrm{D}$. It is called trivial functional dependence of XML.

\subsection{Multiple-Valued Dependence of XML}

Definition 3 (Multiple-valued dependence of XML, XMVD) Given DTD D, T is a complete tree that satisfies $\mathrm{D} . \mathrm{P}=\left\{\mathrm{p}_{1}, \ldots, \mathrm{p}_{\mathrm{k}}\right\}, \mathrm{Q}=\left\{\mathrm{q}_{1}, \ldots, \mathrm{q}_{\mathrm{m}}\right\}$ and $\mathrm{R}=\left\{\mathrm{r}_{1}, \ldots, \mathrm{r}_{\mathrm{s}}\right\}$ are all the routes of Paths(D), and $\mathrm{k} \geq 1, \mathrm{~m} \geq 1, \mathrm{~s} \geq 1,\left\{\left\{\mathrm{p}_{1}, \ldots, \mathrm{p}_{\mathrm{k}}\right\} \cup\left\{\mathrm{q}_{1}, \ldots, \mathrm{q}_{\mathrm{m}}\right\} \cup\left\{\mathrm{r}_{1}, \ldots, \mathrm{r}_{\mathrm{s}}\right\}\right\} \subset$ Paths(D). To any two different route Cases: $\mathrm{V}=\left\{v_{1}^{1}, v_{2}^{1} \ldots \ldots v_{l-1}^{1}, v_{l}^{1}, \ldots, v_{1}^{m}, v_{2}^{m} \ldots \ldots . v_{n-1}^{m}, v_{n}^{m}\right\}$ And $\mathrm{W}=\left\{w_{1}^{1}, w_{2}^{1}\right.$. $\left.\ldots{ }^{w_{l-1}^{1}} \cdot w_{l}^{1}, \ldots,{ }_{1}^{w_{1}^{m}} \cdot w_{2}^{m} \ldots \ldots w_{n-1}^{m} \cdot w_{n}^{m}\right\}(1 \leq \mathrm{i} \leq \mathrm{m}, 1 \leq \mathrm{t})$, if the following conditions are satisfied, the multi-valued dependence of XML $\left(\mathrm{p}_{1}, \ldots, \mathrm{p}_{\mathrm{k}} \rightarrow \rightarrow \mathrm{q}_{1}, \ldots, \mathrm{q}_{\mathrm{m}} \mid \mathrm{r}_{1}, \ldots, \mathrm{r}_{\mathrm{s}}\right)$ is presented in mode $\mathrm{D}$.

$\operatorname{Val}\left({ }^{v_{t}^{i}}\right) \neq \operatorname{val}\left({ }^{w_{t}^{i}}\right)$

(1) $\operatorname{val}\left(v_{t}^{i}\right) \neq \operatorname{val}\left(w_{t}^{i}\right)$; 
(2) There exists a route $r j \in R(1 \leq j \leq s)$, which has two nodes $z_{1} 、 z_{2}$. Then it has conditions that $\mathrm{z} 1 \in \operatorname{Nodes}\left(\mathrm{x}_{\mathrm{ij}}, \mathrm{r}_{\mathrm{j}}\right)$ and $\mathrm{z} 2 \in \operatorname{Nodes}\left(\mathrm{y}_{\mathrm{i},}, \mathrm{r}_{\mathrm{j}}\right)$ which will make $\operatorname{val}\left(\mathrm{z}_{1}\right) \neq \operatorname{val}\left(\mathrm{z}_{2}\right)$;

(3) For all the routes $p h \in P(1 \leq h \leq k)$, there exist two nodes $z_{3}$ and $z_{4}$, within which, $\mathrm{z}_{3} \in \operatorname{Nodes}\left(\mathrm{x}_{\mathrm{ijh}}, \mathrm{p}_{\mathrm{h}}\right)$ and $\mathrm{z} 4 \in \operatorname{Nodes}\left(\mathrm{y}_{\mathrm{ijh}}, \mathrm{p}_{\mathrm{h}}\right)$ which will make $\operatorname{val}\left(\mathrm{z}_{3}\right)=\operatorname{val}\left(\mathrm{z}_{4}\right)$;

(4) There exists a route $v_{1}^{v_{1}^{i}} v_{2}^{\prime i} \ldots v_{t-1}^{\prime i} v^{\prime i}$ in $\operatorname{Paths}\left(\mathrm{q}_{\mathrm{i}}\right)$, which will make $\operatorname{val}\left(v_{t}^{i}\right)=\operatorname{val}\left(v_{t}^{i}\right)$. And there exists a node $z^{\prime} 1$ at $\operatorname{Nodes}\left(x^{x_{i j}}, r_{\mathrm{j}}\right)$, and it will make $\operatorname{val}\left(\mathrm{z}_{1}^{\prime}\right)=\operatorname{val}\left(\mathrm{z}_{2}\right)$; there exists a node $\mathrm{z}_{3}^{\prime}$ at $\operatorname{Nodes}\left(\mathrm{x}_{\mathrm{ijh}}^{\prime}, \mathrm{p}_{\mathrm{h}}\right)$, and it will make $\operatorname{val}\left(\mathrm{z}_{3}^{\prime}\right)=\operatorname{val}\left(\mathrm{z}_{3}\right)$;

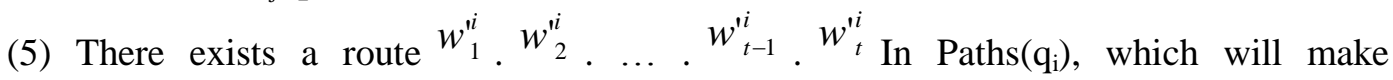
$\operatorname{val}\left(w_{t}^{i}\right)=\operatorname{val}\left(w_{t}^{i}\right)$. And there exists a node $\mathrm{z}_{2}^{\prime}$ at $\operatorname{Nodes}\left(\mathrm{y}_{\mathrm{ij}}^{\prime}, \mathrm{r}_{\mathrm{j}}\right)$, and it will make $\operatorname{val}\left(\mathrm{z}_{2}^{\prime}\right)=\operatorname{val}\left(\mathrm{z}_{1}\right)$; there exists a node $\mathrm{z}_{4}^{\prime}$ at $\operatorname{Nodes}\left(\mathrm{y}_{\mathrm{ijh}}^{\prime}, \mathrm{p}_{\mathrm{h}}\right)$, and it will make val $\left(\mathrm{z}_{4}^{\prime}\right)=\operatorname{val}\left(\mathrm{z}_{4}\right)$.

Among which, $x \mathrm{ij}=\left\{\mathrm{v} \mid \mathrm{v} \in\left\{v_{1}^{i}, \ldots, v^{i}\right\}\right.$ and $\left.\mathrm{v} \in \mathrm{N}\left(\mathrm{r}_{\mathrm{j}} \cap \mathrm{q}_{\mathrm{i}}\right)\right\}, \mathrm{yij}=\left\{\mathrm{v} \mid \mathrm{v} \in\left\{w_{1}^{i}, \ldots, w_{t}^{i}\right\}\right.$ and $\left.\mathrm{v} \in \mathrm{N}\left(\mathrm{r}_{\mathrm{j}} \cap \mathrm{q}_{\mathrm{i}}\right)\right\}, \quad \mathrm{x}_{\mathrm{ijh}}=\left\{\mathrm{v} \mid \mathrm{v} \in\left\{v_{1}^{i}, \ldots, v_{t}^{i}\right\}\right.$ and $\left.\mathrm{v} \in \mathrm{N}\left(\mathrm{p}_{\mathrm{h}} \cap \mathrm{r}_{\mathrm{j}} \cap \mathrm{q}_{\mathrm{i}}\right)\right\}, \quad \mathrm{yijh}=\left\{\mathrm{v} \mid \mathrm{v} \in\left\{w_{1}^{i}, \ldots, w_{t}^{i}\right\}\right.$ and $\left.\mathrm{v} \in \mathrm{N}\left(\mathrm{p}_{\mathrm{h}} \cap \mathrm{r}_{\mathrm{j}} \cap \mathrm{q}_{\mathrm{i}}\right)\right\} ; \mathrm{x}_{\mathrm{ij}}^{\prime}=\left\{\mathrm{v} \mid \mathrm{v} \in\left\{v_{1}^{i}, \ldots, v_{\mathrm{t}}^{i}\right\}\right.$ and $\left.\mathrm{v} \in \mathrm{N}\left(\mathrm{r}_{\mathrm{j}} \cap \mathrm{q}_{\mathrm{i}}\right)\right\}, \mathrm{y}_{\mathrm{ij}}^{\prime}=\left\{\mathrm{v} \mid \mathrm{v} \in\left\{w_{1}^{i}, \ldots, w_{t}^{w_{i}^{i}}\right\}\right.$ and $\left.\mathrm{v} \in \mathrm{N}\left(\mathrm{r}_{\mathrm{j}} \cap \mathrm{q}_{\mathrm{i}}\right)\right\}, \mathrm{x}_{\mathrm{ijh}}^{\prime}=\left\{\mathrm{v} \mid \mathrm{v} \in\left\{v_{1}^{i i}, \ldots, v^{i i}\right\}\right.$ and $\left.\mathrm{v} \in \mathrm{N}\left(\mathrm{p}_{\mathrm{h}} \cap \mathrm{r}_{\mathrm{j}} \cap \mathrm{q}_{\mathrm{i}}\right)\right\}, \mathrm{y}_{\mathrm{ijh}}^{\prime}=\left\{\mathrm{v} \mid \mathrm{v} \in\left\{w_{1}^{i i}, \ldots, w_{t}^{i t}\right\}\right.$ and $\left.\mathrm{v} \in \mathrm{N}\left(\mathrm{p}_{\mathrm{h}} \cap \mathrm{r}_{\mathrm{j}} \cap \mathrm{q}_{\mathrm{i}}\right)\right\}$ 。

From Definition 2, it can be known that route $r_{j} \cap q_{i}$ is the prefix of $q_{i}$. Therefore, there is only one node which is both in set $\left\{v_{1}^{i}, \ldots,{ }^{v_{i}^{i}}\right\}$ and set $\mathrm{N}\left(\mathrm{r}_{\mathrm{j}} \cap q_{\mathrm{i}}\right)$. Then it can be concluded that only one node is included in xij. In a similar way, there is only one node included in $\mathrm{y}_{\mathrm{ij}}, \mathrm{x}_{\mathrm{ijh}}, \mathrm{y}_{\mathrm{ijh}}, \mathrm{x}_{\mathrm{ij}}^{\prime}, \mathrm{y}_{\mathrm{ij}}^{\prime}, \mathrm{x}_{\mathrm{ijh}}^{\prime}$ and $\mathrm{y}_{\mathrm{ijh}}^{\prime}$. It can be also known that XMVD is symmetrical, namely, $X M V D ; p_{1}, \ldots, p_{k} \rightarrow \rightarrow q_{1}, \ldots, q_{m} \mid r_{1}, \ldots, r_{s}$ is presented; if and only if $\mathrm{XMVD} ; \mathrm{p}_{1}, \ldots, \mathrm{p}_{\mathrm{k}} \rightarrow \rightarrow \mathrm{r}_{1}, \ldots, \mathrm{r}_{\mathrm{s}} \mid \mathrm{q}_{1}, \ldots, \mathrm{q}_{\mathrm{m}}$ is presented.

Case 3: In view of document tree T1's satisfying the multiple-valued dependence of XML in

Figure.1:

Courses.Course.Cno $\rightarrow \rightarrow$ Courses.Course.Student.Sno|Courses.Course.Student.Teacher.Tno. Here $\mathrm{k}=\mathrm{m}=\mathrm{s}=1$, provided $\mathrm{v}_{1}^{1}, v_{2}^{1} \ldots . v_{n-1}^{1} \cdot v_{n}^{1}$ be the case $\mathrm{v}_{1} \cdot \mathrm{v}_{2} \cdot \mathrm{v}_{8} \cdot \mathrm{v}_{12}$, and $w_{1}^{1}, w_{2}^{1} \ldots . w_{n-1}^{1} \cdot w_{n}^{1}$ the case $\mathrm{v}_{1} \cdot \mathrm{v}_{3} \cdot \mathrm{v}_{11} \cdot \mathrm{v}_{21}$. $\quad \mathrm{v}_{1} \cdot \mathrm{v}_{2} \cdot \mathrm{v}_{8} \cdot \mathrm{v}_{12} \in$ Paths(Courses.Course.Student.Sno) and $\mathrm{v}_{1} \cdot \mathrm{v}_{3} \cdot \mathrm{v}_{11} \cdot \mathrm{v}_{21} \in \operatorname{Paths}\left(\right.$ Courses.Course.Student.Sno), $\operatorname{val}\left(\mathrm{v}_{12}\right) \neq \operatorname{val}\left(\mathrm{v}_{21}\right)$, satisfying condition (1) in $\quad$ definition 3.2 since $\quad \mathrm{x}_{11}=\mathrm{v}_{8}, \mathrm{y}_{11}=\mathrm{v}_{11}, \mathrm{x}_{111}=\quad \mathrm{v}_{2}, \mathrm{y}_{111}=\mathrm{v}_{3}$, $\operatorname{Nodes}\left(\mathrm{x}_{11}\right.$,Courses.Course.Student.Teacher.Tno $)=\left\{\mathrm{v}_{23}\right\}$,

Nodes $\left(\mathrm{y}_{11}\right.$,Courses. Course.Student.Teacher.Tno) $=\left\{\mathrm{v}_{29}\right\}$. Provided $\mathrm{z}_{1}=\mathrm{v}_{23}, \mathrm{z}_{2}=\mathrm{v}_{29}$, within which

Nodes $\left(\mathrm{x}_{11}\right.$,Courses.Course.Student.Teacher.Tno $), \mathrm{z}_{2} \in \operatorname{Nodes}\left(\mathrm{y}_{11}\right.$,Courses.Course.Student.

Teacher.Tno) and $\operatorname{val}\left(\mathrm{v}_{23}\right) \neq \operatorname{val}\left(\mathrm{v}_{29}\right)$, satisfying condition (2) in definition 2 : $\operatorname{Nodes}\left(\mathrm{x}_{111}\right.$, Courses.Course.Cno $)=\left\{\mathrm{v}_{2}\right\}, \operatorname{Nodes}\left(\mathrm{y}_{111}\right.$, Courses.Course.Cno $)=\left\{\mathrm{v}_{3}\right\}, \quad$ and $\operatorname{val}\left(\mathrm{z}_{3}\right)=\operatorname{val}\left(\mathrm{z}_{4}\right)$, satisfying condition $(3)$ in definition 2 ; provided $v_{1}^{11} \cdot v_{2}^{11} \ldots . v_{n-1}^{1} \cdot v_{\mathrm{n}}^{11}$ be the case $\mathrm{v}_{1} \cdot \mathrm{v}_{3} \cdot \mathrm{v}_{10} \cdot \mathrm{v}_{18}$, then $\operatorname{val}\left(v_{n}^{{ }^{\prime}}\right)=\mathrm{val}\left(v_{n}^{1}\right)$, and $\mathrm{x}_{{ }_{11}}=\mathrm{v}_{10}, \mathrm{x}_{111}^{\prime}=\mathrm{v}_{3}$. Provided $\mathrm{z}_{1}^{\prime}=$ $\mathrm{v}_{27}, \mathrm{z}_{1}{ }_{1} \in \quad$ Nodes $\left(\mathrm{x}_{11}{ }_{11}\right.$,Courses.Course.Student.Teacher.Tno $) \quad$ and $\operatorname{val}\left(\mathrm{z}_{1}^{\prime}\right)=\operatorname{val}\left(\mathrm{z}_{2}\right)$.Provided $\quad \mathrm{z}_{3}^{\prime}=\mathrm{v}_{2}, \mathrm{z}_{3}^{\prime} \in \operatorname{Nodes}\left(\mathrm{x}_{111}^{\prime}\right.$, Courses.Course.Cno $)$, and $\operatorname{val}\left(z_{3}^{\prime}\right)=\operatorname{val}\left(z_{3}\right)$, satisfying condition (4) in definition 2 . Provided $w_{1}^{w_{1}^{\prime \prime}} \cdot w_{2}^{\prime \prime} \ldots \ldots w_{n-1}^{w^{\prime \prime}} \cdot w_{n}^{\prime \prime}$ be $\mathrm{v}_{1} \cdot \mathrm{v}_{2} \cdot \mathrm{v}_{9} \cdot \mathrm{v}_{15}$, then $\operatorname{val}\left(w_{n}^{\prime 1}\right)=\operatorname{val}\left(w_{n}^{1}\right) \circ \mathrm{y}_{11}^{\prime}=\mathrm{v}_{9}, \mathrm{y}_{111}^{\prime}=\mathrm{v}_{2}$ 。 Provided $\mathrm{z}_{2}^{\prime}=$ $\mathrm{v}_{25}, \mathrm{z}_{2}^{\prime} \in \operatorname{Nodes}\left(\mathrm{y}_{11}^{\prime}\right.$,Courses.Course.Student.Teacher.Tno $)$, and $\operatorname{val}\left(\mathrm{z}_{2}^{\prime}\right)=\operatorname{val}\left(\mathrm{z}_{1}\right)$. Provided $\mathrm{z}_{4}^{\prime}=\mathrm{v}_{2}, \mathrm{z}_{4}{ }_{4} \in \operatorname{Nodes}\left(\mathrm{y}_{111}^{\prime}\right.$, Courses.Course.Cno), and $\operatorname{val}\left(\mathrm{z}_{4}{ }_{4}\right)=\operatorname{val}\left(\mathrm{z}_{4}\right)$, satisfying condition (5) in definition 2 . Therefore, T1satisfiesXMVD;Courses.Course.Cno $\rightarrow \rightarrow$ Courses.Course.Student.Sno|Courses.

Course.Student.Teacher.Tno.

Definition 4 (trivial multiple-valued functional dependence of XML): Given DTD D, T is a complete tree that satisfies $D$. Provided $P=\left\{\mathrm{p}_{1}, \ldots, \mathrm{p}_{\mathrm{k}}\right\}$ and $\mathrm{Q}=\left\{\mathrm{q}_{1}, \ldots, \mathrm{q}_{\mathrm{m}}\right\}$ are route sets of $\mathrm{D}$ 
$(\mathrm{k} \geq 1, \mathrm{~m} \geq 1,(\mathrm{P} \cup \mathrm{Q}) \subset \mathrm{Paths}(\mathrm{D}))$. If $\mathrm{P} \subset \mathrm{Q}$ or $\mathrm{VPaths}(\mathrm{D}) \subset(\mathrm{P} \cup \mathrm{Q})$, the trivial multiple-valued functional dependence: $\mathrm{p}_{1}, \ldots, \mathrm{p}_{\mathrm{k}} \rightarrow \rightarrow \mathrm{q}_{1}, \ldots, \mathrm{q}_{\mathrm{m}}$, is presented in mode $\mathrm{D}$, which is called trivial multiple-valued functional dependence.

Based on the definitions of XFD and XMVD above, XFD will be proved as a particular case of XMVD.

Lemma 1: Given DTD D, T is a complete tree that satisfies D. Provided $p_{h}, r_{j}, q_{i} \in D$, $1 \leq \mathrm{h} \leq \mathrm{k}, 1 \leq \mathrm{i} \leq \mathrm{m}$ and $1 \leq \mathrm{j} \leq \mathrm{s}$. If tree $\mathrm{T}$ satisfies XFD which satisfies $\mathrm{p}_{1}, \ldots, \mathrm{p}_{\mathrm{k}} \rightarrow \mathrm{q}_{1}, \ldots, \mathrm{q}_{\mathrm{m}}$, then $\mathrm{T}$ will satisfy XMVD which satisfies $\mathrm{p}_{1}, \ldots, \mathrm{p}_{\mathrm{k}} \rightarrow \rightarrow \mathrm{q}_{1}, \ldots, \mathrm{q}_{\mathrm{m}} \mid \mathrm{r}_{1}, \ldots, \mathrm{r}_{\mathrm{s}}\left(\mathrm{R}=\left\{\mathrm{r}_{1}, \ldots, \mathrm{r}_{\mathrm{s}}\right\} \in \mathrm{D}\right)$.

Prove: Suppose that there exist two different route Cases in Paths $\left(\mathrm{q}_{\mathrm{i}}\right): v_{1}^{i}, v_{2}^{i} \ldots v_{\mathrm{t}-1}^{i} \cdot v_{t}^{i}$ and $\mathrm{w}_{1}^{i} \cdot w_{2}^{i} \ldots \ldots w_{t-1}^{i} \cdot w_{t}^{i}(1 \leq \mathrm{t})$, which satisfies val $\left(v_{t}^{i}\right) \neq \operatorname{val}\left(w_{t}^{i}\right)$. According to the definition of $\mathrm{XFD}$, it can be known that $\operatorname{val}\left(\operatorname{Nodes}\left(\mathrm{x}_{\mathrm{ij}}, \mathrm{p}_{\mathrm{i}}\right)\right) \cap \operatorname{val}\left(\operatorname{Nodes}\left(\mathrm{y}_{\mathrm{ij}}, \mathrm{p}_{\mathrm{i}}\right)\right)=\varnothing$, then it can be known $\mathrm{p}_{\mathrm{i}}$ is key. Then, it can be concluded that it doesn't satisfies the condition 3 of the definition of XMVD. Namely, there is no existence to all $\mathrm{ph}(1 \leq \mathrm{h} \leq \mathrm{k})$ which will have two nodes $\mathrm{z}_{3}$ and $\mathrm{z}_{4}$ $\left(\mathrm{z}_{3} \in \operatorname{Nodes}\left(\mathrm{x}_{\mathrm{ijh}}, \mathrm{p}_{\mathrm{h}}\right), \mathrm{z} 4 \in \operatorname{Nodes}\left(\mathrm{y}_{\mathrm{ijh}}, \mathrm{p}_{\mathrm{h}}\right)\right)$ to make $\operatorname{val}\left(\mathrm{z}_{3}\right)=\operatorname{val}\left(\mathrm{z}_{4}\right)$. Therefore, $\mathrm{T}$ satisfies the multiple-valued dependence: $\mathrm{p}_{1}, \ldots, \mathrm{p}_{\mathrm{k}} \rightarrow \rightarrow \mathrm{q}_{1}, \ldots, \mathrm{q}_{\mathrm{m}} \mid \mathrm{r}_{1}, \ldots, \mathrm{r}_{\mathrm{s}}$.

Definition 5 (logical entailment) Given DTD D, and Paths(D) is a route way in D, and $\Sigma$ is a data dependence set in $\mathrm{D}$. If each complete tree $\mathrm{T}$ which satisfies $\sum$ also satisfies $\mathrm{P} \rightarrow \rightarrow \mathrm{Q} \mid \mathrm{R}$ or $\mathrm{P} \rightarrow \mathrm{Q}$, then $\sum$ logically entails $\mathrm{P} \rightarrow \rightarrow \mathrm{Q} \mid \mathrm{R}$ or $\mathrm{P} \rightarrow \mathrm{Q}$, marked as $\sum \models \mathrm{P} \rightarrow \rightarrow \mathrm{Q} \mid \mathrm{R}$ or $\sum \models \mathrm{P} \rightarrow \mathrm{Q}$.

Definition 6 (Closure) Given DTD, Paths(D) is a set of all routes in D. Suppose that $\sum$ is a mixed set of XFD and XMVD, and the set of all XFD and XMVD which is logically entailed by $\sum$ is called the closure of XFD and XMVD, which is marked as $\sum+$. Namely $\sum+=\left\{\mathrm{P} \rightarrow \rightarrow \mathrm{Q} \mid \mathrm{R}\right.$ or $\mathrm{P} \rightarrow \mathrm{Q}\left|\sum \models \mathrm{P} \rightarrow \rightarrow \mathrm{Q}\right| \mathrm{R}$ or $\left.\sum \models \mathrm{P} \rightarrow \mathrm{Q}\right\}$; and the route set $\mathrm{P} \subseteq \mathrm{Paths}(\mathrm{D})$. Hence, the closure of route set $\mathrm{P}$ which has relative to $\sum$ is marked as $\mathrm{P}+$. It's a set of $\mathrm{q}$ which has all route that satisfies $\mathrm{P} \rightarrow \mathrm{q}$ by means of using rule of inference set from set $\sum$ : $\mathrm{P}+=\left\{\right.$ route $\mathrm{q} \mid \mathrm{P} \rightarrow \mathrm{q}$ in $\left.\sum+\right\}$.

Definition 7 (set equivalence) Given DTD D, T is a complete tree that satisfies D. Definite VPaths $(\mathrm{D})=\left\{\mathrm{p} \mid \mathrm{last}(\mathrm{p}) \in\left(\mathrm{E}_{2} \cup \mathrm{A}\right)\right\}$. Order $\mathrm{P}=\left\{\mathrm{p}_{1}, \ldots, \mathrm{p}_{\mathrm{k}}\right\}$ and $\mathrm{Q}=\left\{\mathrm{q}_{1}, \ldots, \mathrm{q}_{\mathrm{k}}\right\}$, and $\mathrm{P}$ and $Q$ are route set of $T, k \geq 1$. If it satisfies last $\left(p_{i}\right)=\operatorname{last}\left(q_{i}\right)$ and the values of the end nodes of pi and qi are equal, the values of $\mathrm{P}$ and $\mathrm{Q}$ will be equal, marked as $\mathrm{P}_{\mathrm{val}}=\mathrm{Q}$.

\section{Inference Rules Set}

The method of solving the decision problem of logical implication is to derive some more dependencies established from a group of known dependency sets. While the primary method when solving the decision of logical implication, in general, is to introduce inference rules. Correctness of inference rules means "the dependencies derived by using inference rules set from dependency set $\sum$ are certainly in $\Sigma^{+}$", completeness means "all dependencies in $\Sigma^{+}$can be derived by using inference rules set in $\Sigma$ ". The correctness ensures that all dependencies derived are correct, and the completeness ensures that all implicated dependencies can be derived. Which ensure the validity and reliability of derivation. Here is a group of inference rules sets under the coexistence of XFD and XMVD.

(Reflexivity of XFD) If $\mathrm{Q} \subseteq \mathrm{P}$, then $\mathrm{P} \rightarrow \mathrm{Q}$

(Augmentation of XFD) If $\mathrm{P} \rightarrow \mathrm{Q}$ and $\mathrm{S} \subseteq \mathrm{R} \subseteq$ Paths(D), then $\mathrm{PR} \rightarrow \mathrm{Q}$

(Transitivity of XFD) If $\mathrm{P} \rightarrow \mathrm{Q}, \mathrm{Q} \rightarrow \mathrm{R}$, then $\mathrm{P} \rightarrow \mathrm{R}$

(Supplement rule of XMVD) If $\mathrm{P} \rightarrow \rightarrow \mathrm{Q}$, then $\mathrm{P} \rightarrow \rightarrow \mathrm{R}, \mathrm{R}=\mathrm{Paths}(\mathrm{D})-\mathrm{P}-\mathrm{Q}$

(Reflexive rule of $\mathrm{XMVD}$ ) If $\mathrm{Q} \subseteq \mathrm{P}$, then $\mathrm{P} \rightarrow \rightarrow \mathrm{Q}$; This rule can also be defined as trivial multivalued dependency.

(Augmentation rule of $\mathrm{XMVD}$ ) If $\mathrm{P} \rightarrow \rightarrow \mathrm{Q}$, and $\mathrm{V} \subseteq \mathrm{W} \subseteq \mathrm{Paths}(\mathrm{D})$, then $\mathrm{PW} \rightarrow \rightarrow \mathrm{QV}$ 
(Transmission rule of $\mathrm{XMVD}$ ) If $\mathrm{P} \rightarrow \rightarrow \mathrm{Q}, \mathrm{Q} \rightarrow \rightarrow \mathrm{V}$, then $\mathrm{P} \rightarrow \rightarrow \mathrm{V}-\mathrm{Q}$

(Plyability) If $\mathrm{P} \rightarrow \mathrm{Q}$, then $\mathrm{P} \rightarrow \rightarrow \mathrm{Q}$

(Connectivity) If $\mathrm{P} \rightarrow \rightarrow \mathrm{Q}, \mathrm{R} \subseteq \mathrm{Q}$, and there $\mathrm{W} \subseteq$ Paths $(\mathrm{D})$ meet $\mathrm{W} \cap \mathrm{Q}=\varnothing$ and $\mathrm{W} \rightarrow \mathrm{R}$, then $\mathrm{P} \rightarrow \mathrm{R}$

(Complement rule of XMVD) If $\mathrm{P} \rightarrow \rightarrow \mathrm{Q}, \mathrm{P} \rightarrow \rightarrow \mathrm{R}$, then $\mathrm{P} \rightarrow \rightarrow \mathrm{QR}$

(Residual rule of XMVD) If $\mathrm{P} \rightarrow \rightarrow \mathrm{Q}, \mathrm{P} \rightarrow \rightarrow \mathrm{R}$, then $\mathrm{P} \rightarrow \rightarrow \mathrm{Q}-\mathrm{R}, \mathrm{P} \rightarrow \rightarrow \mathrm{R}-\mathrm{Q}$

(Intersection rule of XMVD) If $\mathrm{P} \rightarrow \rightarrow \mathrm{Q}, \mathrm{P} \rightarrow \rightarrow \mathrm{R}$, then $\mathrm{P} \rightarrow \rightarrow \mathrm{Q} \cap \mathrm{R}$

(Pseudotransitivity rule of $\mathrm{XMVD}$ ) If $\mathrm{P} \rightarrow \rightarrow \mathrm{Q}$, WQ $\rightarrow \rightarrow \mathrm{R}$, then $\mathrm{WX} \rightarrow \rightarrow \mathrm{Z}-\mathrm{WY}$

(Mixed pseudotransitivity rule) If $\mathrm{X} \rightarrow \rightarrow \mathrm{Y}, \mathrm{X} \rightarrow \rightarrow \mathrm{YZ}$, then $\mathrm{X} \rightarrow \rightarrow \mathrm{Z}-\mathrm{Y}$

\subsection{Correctness of Inference Rules Set}

The followings will prove that the Rule (1) to (14) is valid for the derivation of logical implication relationship between XFD and XMVD.

To prove conveniently, it is assumable all XFD and XMVD in the following proofs are dependencies based on the document tree $\mathrm{T}$.

(1) Condition (1) in definition1 shows that $\mathrm{Q} \subseteq \mathrm{P}$ meets the definition of XFD. Therefore the rule is established.

(2) Provided that XFD: $\mathrm{P} \rightarrow \mathrm{Q}$ is established, while $\mathrm{PR} \rightarrow \mathrm{QS}$ is not . Since $\mathrm{P} \rightarrow \mathrm{Q}$ is established, when path $\mathrm{q}_{\mathrm{i}}$ meets the Condition(1),Definition1, it still meets Condition(1) ,Definition 1, when the left path extends to $\left\{\mathrm{p}_{1}, \ldots, \mathrm{p}_{\mathrm{k}}, \mathrm{r}_{1}, \ldots, \mathrm{r}_{\mathrm{g}}\right\}$, (2) when path $\mathrm{q}_{\mathrm{i}}$ meets Condition(2) ,Definition3.1, if $r_{t}=q_{i}$ meets the Condition(1) ,Definition1, XFD PR $\rightarrow$ Qis established when the left path set extends to $\left\{\mathrm{p}_{1}, \ldots, \mathrm{p}_{\mathrm{k}}, \mathrm{r}_{1}, \ldots, \mathrm{r}_{\mathrm{g}}\right\}$, and it meets the Condition(1),Definition1; $\forall \mathrm{t}$, if $r$ meets Condition(2),Definition1. Namely,Last $\left(\mathrm{r}_{\mathrm{t}}\right) \notin \mathrm{E}_{1}$ and $\operatorname{val}\left(\operatorname{Nodes}\left(\mathrm{x}_{\mathrm{it}}, \mathrm{r}_{\mathrm{t}}\right)\right) \cap \operatorname{val}\left(\operatorname{Nodes}\left(\mathrm{y}_{\mathrm{it}}, \mathrm{r}_{\mathrm{t}}\right)\right) \neq \varnothing$ or $\operatorname{Last}\left(\mathrm{r}_{\mathrm{t}}\right) \in \mathrm{E}_{1}$ and $\mathrm{x}_{\mathrm{it}}=\mathrm{y}_{\mathrm{it}}$, then $\mathrm{XFD} P R \rightarrow \mathrm{Q}$ is established; And because $\mathrm{S} \subseteq \mathrm{R} \subseteq$ Paths(D), then $\mathrm{PR} \rightarrow \mathrm{QS}$ is established according to Definition 1 as for path $s_{i}$ meets $r_{i}=s_{i}$. If $\exists t$,making $r_{t}$ fail to meet Condition(2), Definition 1 ,it shows that all the instance path sets which correspond tothe left path sets are different, and in this case, that $P R \rightarrow Q S$ is established can be certainly derived. $P=\left\{p_{1}, \ldots, p_{k}\right\}, 1 \leq j \leq k$; $\mathrm{Q}=\left\{\mathrm{q}_{1}, \ldots, \mathrm{q}_{\mathrm{m}}\right\}, 1 \leq \mathrm{i} \leq \mathrm{m} ; \mathrm{R}=\left\{\mathrm{r}_{1}, \ldots, \mathrm{r}_{\mathrm{g}}\right\}, 1 \leq \mathrm{t} \leq \mathrm{g} ; \mathrm{S}=\left\{\mathrm{s}_{1}, \ldots, \mathrm{s}_{\mathrm{h}}\right\}, 1 \leq \mathrm{d} \leq \mathrm{h}$ are included.

(3) Provided that XFD $\mathrm{P} \rightarrow \mathrm{Q}$ and $\mathrm{Q} \rightarrow \mathrm{R}$ are established, according to Definition1, as to two arbitrary path instance sets $\mathrm{P}_{1}$ and $\mathrm{P}_{2}$, if $\mathrm{P}_{1 \mathrm{val}}=\mathrm{P}_{2}, \mathrm{Q}_{1 \mathrm{val}}=\mathrm{Q}_{2}$ must be corresponding. And since $X F D Q \rightarrow R$ is established, as to two path instance sets $Q_{1}$ and $Q_{2}$, and $Q_{1 \text { val }}=Q_{2}, R_{1 \text { val }}=$ $R_{2}$ must be corresponding. Namely, to two arbitrary path instance sets $P_{1}$ and $P_{2, i}$ if $P_{1 v a l}=$ $\mathrm{P}_{2}$, then $\mathrm{R}_{1 \text { val }}=\mathrm{R}_{2}$ must be corresponding. Hence, $\mathrm{XFD} \mathrm{P} \rightarrow \mathrm{R}$ is established.

(4)The rule of XMVD can be derived directly by the definition of XMVD.

(5)The rule of XMVD can be derived directly by the definition of XMVD.

(6)Using proof by contradiction: Namely, assuming that $\mathrm{P} \rightarrow \rightarrow \mathrm{Q}$ is established while $\mathrm{PW} \rightarrow \rightarrow \mathrm{QV}$ is not. Since $\mathrm{P} \rightarrow \rightarrow \mathrm{Q}$ is established, definition3 shows that there is a path ${ }^{v_{1}^{i}} . v^{{ }_{2}}{ }_{2}$. $\ldots . v_{t-1}^{i} . v_{t}^{i i}$ InPaths $\left(\mathrm{q}_{\mathrm{i}}\right)$, which makes val $\left(v_{t}^{v_{i}}\right)=\mathrm{val}\left(v_{t}^{i}\right)$. Meanwhile, there is a crunode $\mathrm{z}_{1}^{\prime}$ in $\operatorname{Nodes}\left(x_{i j}^{\prime}, \mathrm{r}_{\mathrm{j}}\right)$, which makes $\operatorname{val}\left(\mathrm{z}_{1}^{\prime}\right)=\operatorname{val}\left(\mathrm{z}_{2}\right)$, and there is a crunode $\mathrm{z}_{3}^{\prime}$, making $\operatorname{val}\left(\mathrm{z}_{3}^{\prime}\right)=\operatorname{val}\left(\mathrm{z}_{3}\right)$; There is a path ${w_{1}^{i}}_{{ }_{1}} \cdot w_{2}^{i i} \ldots \ldots \cdot^{w_{t-1}^{i}} \cdot w_{t}^{i}$, which makes val $\left(w_{t}^{i i}\right)=\operatorname{val}\left(w_{t}^{i}\right)$, while, there is a crunode $z_{2}^{\prime}$ in $\operatorname{Nodes}\left(y_{i j}^{\prime}, r_{j}\right)$, making $\operatorname{val}\left(z_{2}^{\prime}\right)=\operatorname{val}\left(z_{1}\right)$, and there is a crunode $z_{4}^{\prime}$ in $\operatorname{Nodes}\left(\mathrm{y}_{\mathrm{ijh}}^{\prime}, \mathrm{p}_{\mathrm{h}}\right)$, making $\operatorname{val}\left(\mathrm{z}_{4}^{\prime}\right)=\operatorname{val}\left(\mathrm{z}_{4}\right)$. According to reflexive rule, $\mathrm{W} \rightarrow \rightarrow \mathrm{V}$ is established.

To sum up, for all paths u within PW, that there exists a path ${ }^{v_{1}^{i}} \cdot v^{v_{2}^{i}} \ldots . . v_{t-1}^{v_{t-1}} . v_{\mathrm{t}}^{t_{1}^{i}}$ in Paths(ui) making $\operatorname{val}\left(v_{t}^{i i}\right)=\operatorname{val}\left(v_{t}^{i}\right)$. Meanwhile, there is a crunode $\mathrm{z}_{1}^{\prime}$ in $\operatorname{Nodes}\left({ }^{x_{i j}^{\prime}}, \mathrm{r}_{\mathrm{j}}\right)$, which makes $\operatorname{val}\left(\mathrm{z}_{1}^{\prime}\right)=\operatorname{val}\left(\mathrm{z}_{2}\right)$, and there is crunode $\mathrm{z}_{3}^{\prime}$ in $\operatorname{Nodes}\left(\mathrm{x}_{\mathrm{ijh}}^{\prime}, \mathrm{p}_{\mathrm{h}}\right)$, which makes $\operatorname{val}\left(\mathrm{z}_{3}^{\prime}\right)=\operatorname{val}\left(\mathrm{z}_{3}\right)$. Consequently, it meets the Condition (4), Definition3. As for the rest of paths $\mathrm{P}^{\prime}=\mathrm{Path}(\mathrm{D})$ $\{P Q W V\}$,they are subsets both of Paths(D)-PQ and Path(D)-WV, which shows that arbitrary 
paths in $\mathrm{P}^{\prime}$ meet Condition(5), Definition3. Consequently, $\mathrm{PW} \rightarrow \rightarrow \mathrm{QV}$ is established, and thus conflicts with the assumption.

(7) Assuming that XMVD: $\mathrm{Q} \rightarrow \rightarrow \mathrm{V}$ is established:According to Definition3, there is $\mathrm{Q} \rightarrow \rightarrow \mathrm{V}$-Q. Similarly, according to Definition3, when $\mathrm{Q} \rightarrow \rightarrow \mathrm{V}-\mathrm{Q}$ is established, $\mathrm{Q} \rightarrow \rightarrow \mathrm{V}$ is also established. Therefore, it is quite considerable that the condition where $\mathrm{Q} \rightarrow \rightarrow \mathrm{V}$ does not have a common path between the left and the right part.

Each $q \in Q_{T}(p)$ meets $V_{T}(p)=V_{T}(p q)$, which $p, q$ are path instances of $P, Q . V_{T}(p q) \subset V_{T}(p)$ is obvious. If there is a path instance $\mathrm{v} \in \mathrm{V}_{\mathrm{T}}(\mathrm{p})-\mathrm{V}_{\mathrm{T}}(\mathrm{pq})$, and $\mathrm{v}$ belongs to $\mathrm{V}-\mathrm{Q}$, then path instances $\mathrm{p}$ and $\mathrm{q}$ consist in some tree tuples, but not in tree tuples $\mathrm{t}$, within which path instance sets $\mathrm{p}, \mathrm{q}, \mathrm{v}$ are all in tree tuples. It can be further deduced that $\mathrm{Q}_{\mathrm{T}}(\mathrm{pv})$ certainly exclude q.

Since $\mathrm{Q} \rightarrow \rightarrow \mathrm{V}$, according to Definition3, V is only relevant to path set $\mathrm{Q}$, but irrelevant to the other paths. Consequently $\mathrm{V}(\mathrm{pq})=\mathrm{V}(\mathrm{q})$. Since $\mathrm{V}_{\mathrm{T}}(\mathrm{p})=\mathrm{V}_{\mathrm{T}}(\mathrm{pq})$ is established, $\mathrm{q} \in \mathrm{Q}_{\mathrm{T}}(\mathrm{p}), \mathrm{V}_{\mathrm{T}}(\mathrm{p})=\mathrm{V}_{\mathrm{T}}(\mathrm{q})$ are thus established. It can be proved that $\mathrm{V}_{\mathrm{T}}(\mathrm{pw})=\mathrm{V}_{\mathrm{T}}(\mathrm{p})$ be established only under the condition that $q \in Q(p)$, in which $w \in W, W=P a t h s(D)-P V$. Since multi-valued dependency $\mathrm{Q} \rightarrow \rightarrow \mathrm{V}$ fails to maintain a common path between the left and the right part. Consequently it shows $\mathrm{Q} \subset \mathrm{PW}$. There is a map q' consists of $\mathrm{Q}$ against path instance set pw. According to the Definition of $\mathrm{Q}_{\mathrm{T}}(\mathrm{p})$, $\mathrm{q}^{\prime}$ belongs to $\mathrm{Q}_{\mathrm{T}}(\mathrm{p})$; And because $\mathrm{Q} \rightarrow \rightarrow \mathrm{V}$ is established, so is $\mathrm{V}_{\mathrm{T}}(\mathrm{pw})=\mathrm{V}_{\mathrm{T}}\left(\mathrm{q}^{\prime}\right)$. Consequently, $\mathrm{P} \rightarrow \rightarrow \mathrm{V}$ is established.

(8) The inference rules can be derived by Lemma 1.

(9) Assuming that $\mathrm{P} \rightarrow \rightarrow \mathrm{Q}$ and $\mathrm{W} \cap \mathrm{Q}=\Phi$ are established, according to Definition3, $\mathrm{Q}_{\mathrm{T}}(\mathrm{p})=\mathrm{Q}_{\mathrm{T}}(\mathrm{pw})$. Since $\mathrm{R} \subseteq \mathrm{Q}$, then $\mathrm{R}_{\mathrm{T}}(\mathrm{p})=\mathrm{R}_{\mathrm{T}}(\mathrm{pw})$. According to Definition1, it shows $\mathrm{WP} \rightarrow \mathrm{W}$, and because $\mathrm{W} \rightarrow \mathrm{R}$, it is reasonable that $\mathrm{WP} \rightarrow \mathrm{R}$ by transmission rule of XFD. Accordingly $\mathrm{R}_{\mathrm{T}}(\mathrm{pw})$ only contains one element, namely, a path set value of $\mathrm{R}$. And because $R_{T}(p)=R_{T}(p w) . R_{T}(p)$ also only contains a path set value of $R$, which shows $P \rightarrow R$ according to the definition or XFD.

(10) Given that $\mathrm{P} \rightarrow \rightarrow \mathrm{Q}$ and $\mathrm{P} \rightarrow \rightarrow \mathrm{R}$ are established, $\mathrm{P} \rightarrow \rightarrow \mathrm{P} \cup \mathrm{Q}$ and $\mathrm{P} \cup \mathrm{Q} \rightarrow \rightarrow \mathrm{R} \cup \mathrm{Q}$ are established according to the augmentation rule of XMVD. According to the reflexivity of $\mathrm{XMVD}$, it shows that $\mathrm{P} \cup \mathrm{Q} \rightarrow \rightarrow$ Paths $(\mathrm{D})-\mathrm{P} \cup \mathrm{Q} \cup \mathrm{R}$ is established. According to transmission rule of $\mathrm{XMVD}$, it is obvious that $\mathrm{P} \rightarrow \rightarrow$ Paths (D)-P $\cup \mathrm{Q} \cup \mathrm{R}$ is established. According to reflexivity of $\mathrm{XMVD}$, it shows that $\mathrm{P} \rightarrow \rightarrow \mathrm{Q} \cup \mathrm{R}$ is established.

(11) Given that $\mathrm{P} \rightarrow \rightarrow \mathrm{Q}$ and $\mathrm{P} \rightarrow \rightarrow \mathrm{R}$ are established, and according to complement rule of $\mathrm{XMVD}$, it shows that $\mathrm{P} \rightarrow \rightarrow \mathrm{QR}$ is established. According to reflexivity of XMVD, it show that $\mathrm{P} \rightarrow \rightarrow$ Paths (D)-P $\cup \mathrm{Q} \cup \mathrm{R}$ is established. According to $\mathrm{P} \rightarrow \rightarrow \mathrm{R}$ and $\mathrm{P} \rightarrow \rightarrow$ Paths(D)$P \cup Q \cup R$ and complement rule of $X M V D, P \rightarrow \rightarrow(P a t h s(D)-P \cup Q \cup R) \cup R$ is established. By reflexivity of $X M V D$, it is knowable that $P \rightarrow \rightarrow$ Paths $(D)-P \cup(P a t h s(D)-P \cup Q \cup R) \cup R$ is established, that is $\mathrm{P} \rightarrow \rightarrow(\mathrm{Q}-\mathrm{R})-\mathrm{P}$. According to reflexivity of $\mathrm{XMVD}, \mathrm{P} \rightarrow \rightarrow \mathrm{Paths}(\mathrm{D})$ $\mathrm{P} \cup((\mathrm{Q}-\mathrm{R})-\mathrm{P})$, namely, $\mathrm{P} \rightarrow \rightarrow \mathrm{Paths}(\mathrm{D})-(\mathrm{Q}-\mathrm{R})$, is established. Again, by reference to reflexivity of XMVD, it shows that $\mathrm{P} \rightarrow \rightarrow \mathrm{Q}-\mathrm{R}$ is established. The same goes for $\mathrm{P} \rightarrow \rightarrow \mathrm{R}-\mathrm{Q}$.

(12) Given that $\mathrm{P} \rightarrow \rightarrow \mathrm{Q}$ and $\mathrm{P} \rightarrow \rightarrow \mathrm{R}$ are established, and according to complement rule of $\mathrm{XMVD}$, then $\mathrm{P} \rightarrow \rightarrow \mathrm{Q} \cup \mathrm{R}$ is established. According to reflexivity of XMVD, $\mathrm{P} \rightarrow \rightarrow$ Paths(D)$P \cup Q \cup R$ established. According to residual rule of XMVD and complement rule of XMVD, $\mathrm{P} \rightarrow \rightarrow($ Paths(D)-P $\cup \mathrm{Q} \cup \mathrm{R}) \cup(\mathrm{Q}-\mathrm{R})$ established. By reference to reflexivity of XMVD, $\mathrm{P} \rightarrow \rightarrow$ Paths(D)-P $\cup($ Paths $(\mathrm{D})-\mathrm{PQR}) \cup(\mathrm{Q}-\mathrm{R})$, that is $\mathrm{P} \rightarrow \rightarrow(\mathrm{Q} \cap \mathrm{R})-\mathrm{P}$ established. And again, by reference to reflexivity of XMVD $\mathrm{P} \rightarrow \rightarrow \mathrm{Q} \cap \mathrm{R}$ established.

According to augmentation of $\mathrm{XMVD}, \mathrm{W} \cup \mathrm{P} \rightarrow \rightarrow \mathrm{W} \cup \mathrm{Q}$, and according to transitivity of $\mathrm{XMVD}$, it shows $\mathrm{WP} \rightarrow \rightarrow \mathrm{R}-(\mathrm{W} \cup \mathrm{Q})$.

(13) According to augmentation of XMVD, $\mathrm{P} \rightarrow \rightarrow \mathrm{PQ}$; according to reflexivity of XMVD, $\mathrm{W} \rightarrow \mathrm{W}-\mathrm{PQ}$; and because of $\mathrm{PQ} \rightarrow \mathrm{W}$, according to transitivity of $\mathrm{XFD}, \mathrm{PQ} \rightarrow \mathrm{W}-\mathrm{PQ}$; and according to transitivity of XMVD, $\mathrm{P} \rightarrow \rightarrow \mathrm{W}-\mathrm{PQ}$. According to Joint inference rules applied 
to $\mathrm{P} \rightarrow \rightarrow \mathrm{W}-\mathrm{PQ}$ and $\mathrm{PQ} \rightarrow \mathrm{W}-\mathrm{PQ}, \mathrm{P} \rightarrow \mathrm{W}-\mathrm{P} \cup \mathrm{Q}$. According to augmentation of $\mathrm{XFD}, \mathrm{P} \rightarrow \mathrm{P}$ (W-PQ). Hence, $\mathrm{P} \rightarrow \mathrm{P}(\mathrm{W}-\mathrm{Q})$ is established. According to reflexivity of $\mathrm{XFD}, \mathrm{P} \rightarrow \mathrm{W}-\mathrm{Q}$ established.

\subsection{The Completeness of Inference Rules Set}

The concept of path dependency basis should be presented before proving the completeness of inference rules set.

Definition9(minimal base set) gives the complete instance document tree $\mathrm{T}$ which meets DTD $D$ and the set of path set $P=\left\{P_{1}, \ldots, P_{k}\right\}$.Supposing Paths $(D)=P_{1} \cup \ldots \cup P_{k}$, and the minimal base set $(\mathrm{mdb})$ of $\mathrm{P}$ is a partition of path(D) $, \mathrm{S}_{1}, \ldots, \mathrm{S}$,then it makes :

(1) Each Pi is the set of $S_{j}$ which operated by Complement rule.

(2) There is no partition which meets Condition (1) and is less than q; Meanwhile, $1 \leq \mathrm{i} \leq \mathrm{k}, 1 \leq \mathrm{j} \leq \mathrm{q}$.

Definition10 (dependency basis) makes is a set of XFD and XMVD that on the complete instance document tree T which meets DTD D.

Demonstration: the proof of completeness is to prove "XMVD and FD in $\Sigma^{+}$can be derived by using inference rule in $\sum$ " is established

provided that $\sum$ is the set of multi-valued dependency and function dependency, making $\mathrm{P}=\left\{\mathrm{p}_{1}, \ldots, \mathrm{p}_{\mathrm{k}}\right\}$, then $\mathrm{P} \rightarrow \mathrm{P}^{+}, \mathrm{P}^{+} \rightarrow \mathrm{P}$, and $\mathrm{P}_{1}, \ldots, \mathrm{P}_{\mathrm{m}}$ is the dependency set of Paths(D)- $\mathrm{P}^{+}$. Consequently $\mathrm{P}^{+}, \mathrm{P}_{1}, \ldots, \mathrm{Pm}$ is a partition based on Paths(D) Hence it can be proved by $\mathrm{T}$ construction Constructing an instance document tree $\mathrm{T}$ constituted by tree tuples in the number of $2^{\mathrm{m}}$,each tree tuple values 1 on all paths of $\mathrm{P}^{+}$, and values $\mathrm{a}_{\mathrm{i}}, \mathrm{a}_{\mathrm{i}}(0,1)$,on instance path of $\mathrm{P}_{\mathrm{i}}$.The document tree has the following features.Property1:for each XMVD whose right path set is $P_{i}$ is established in T;Property2:if the right of one dependency is the nonempty subset of $\mathrm{P}_{\mathrm{i}}$, then the dependency is established in $\mathrm{T}$, and only if the left of the dependency is non-empty intersection with $\mathrm{P}_{\mathrm{i}} \mathrm{i}=1, \ldots, \mathrm{m}$.

The followings will demonstrate the aforesaid two properties.

(1) Since $\rightarrow \rightarrow P_{\mathrm{i}}$ is established in $T$, based on extension rule, for arbitrary path instance set $\mathrm{Y}, \mathrm{Y} \rightarrow \rightarrow \mathrm{P}_{\mathrm{i}}$ is also established in $\mathrm{T}$.Property1 is proved.

(2)When the dependency is function dependency, if $Y \cap P_{i}$, since the value of each paths is equal in $P_{i}$, further, the values of all paths equal the value of path in $Y \cap P_{i}$, then $\mathrm{Y} \rightarrow \mathrm{P}_{\mathrm{i}}$. For each $\mathrm{Z} \quad \mathrm{P}_{\mathrm{i}}$ and $\mathrm{Z} \quad, \mathrm{Y} \rightarrow \mathrm{Z}$ is established; if $\mathrm{Y} \cap \mathrm{P}_{\mathrm{i}}=, \mathrm{Z} \quad \mathrm{P}_{\mathrm{i}}$ and $\mathrm{Z}$, according to construction $\mathrm{T}, \mathrm{Z}_{\mathrm{T}}(\mathrm{y})$ contains two values 0 and 1 , according to Definition $1, Y \quad Z$ is not established.

When the dependency is multi-valued dependency, if $\mathrm{Y} \cap \mathrm{P} \quad$ i, since the value of each path is equal in $\mathrm{P}_{\mathrm{i}}$, further, the values of all paths equal the value of path in $\mathrm{Y} \cap \mathrm{P}_{\mathrm{i}}$, then $\mathrm{Y} \rightarrow \mathrm{P}_{\mathrm{i}}$. For each $\mathrm{Z} \quad \mathrm{P}_{\mathrm{i}}$ and $\mathrm{Z} \quad, \mathrm{Y} \rightarrow \mathrm{Z}$ is established; therefore $\mathrm{Y} \rightarrow \rightarrow \mathrm{Z}$ is established on $T$. If $Y \cap P_{i} \quad Z \quad P_{i}$ and $Z$, Supposing $r$ is a path in $P_{i}-Z$, according to constitution $T$, as to arbitrary tree elementu, there are two values 0 and 1 of $Z_{\mathrm{T}}(\mathrm{y})$,but because $\mathrm{Z}$ and $\mathrm{r}$ must be assigned the same value, the value of $\mathrm{Z}_{\mathrm{T}}(\mathrm{y}), \mathrm{Z}_{\mathrm{T}}(\mathrm{yr})$ is only one, therefore $\mathrm{Z}_{\mathrm{T}}(\mathrm{y}) \mathrm{Z}_{\mathrm{T}}(\mathrm{yr})$, and $\mathrm{Y} \rightarrow \rightarrow \mathrm{Z}$ is not established on $\mathrm{T}$.

To sum up, Property 2 is proved.

The followings will discuss when meets the conditions of completeness assumption in $\mathrm{T}$.

First of all, supposing $f$ denotes a functional dependency in $\Sigma^{+}$to prove $f$ is established in

$\mathrm{T}$. According to Definition1, f can be formalized as $\mathrm{Q} \rightarrow \mathrm{p}(\mathrm{Q} \rightarrow \mathrm{PW}$ can be indicated as $\mathrm{Q} \rightarrow$ Pand $\mathrm{Q} \rightarrow \mathrm{W}), \mathrm{p}$ denotes a path ,if $\mathrm{p} \mathrm{P}^{+}$, since there is only one value of $\mathrm{P}^{+}$in $\mathrm{T}$, according to Definition1,f is established in $\mathrm{T}$; If $\mathrm{p} \mathrm{P}^{+}$, that is, $\mathrm{p} P$ and $\mathrm{i}=1, \ldots, \mathrm{m}$, if the intersection of $\mathrm{Q}$ and $\mathrm{P}_{\mathrm{i}}$ is empty, according to Definition 10, there is $\mathrm{P} \rightarrow \rightarrow \mathrm{P}_{\mathrm{i}}$. According to connectivity rule, $\mathrm{P} \rightarrow \mathrm{p}$ is established derived by $\mathrm{P} \rightarrow \rightarrow \mathrm{P}_{\mathrm{i}}$ it is conflict with $\mathrm{p} \mathrm{P}^{+}$. Therefore, $\mathrm{Q}$ must have intersection with $\mathrm{P}_{\mathrm{i}}$.According to Property $2, \mathrm{Q} \rightarrow \mathrm{p}$ is established in $\mathrm{T}$. 
Thensupposing $\mathrm{g}$; $\mathrm{Q} \rightarrow \rightarrow \mathrm{V}$ denotes a multi-valued dependency in $\Sigma^{+}$to prove $\mathrm{g}$ is established in $\mathrm{T}$.Known from the analysis of the above, function dependency $\mathrm{Q} \rightarrow \mathrm{V} \cap \mathrm{P}^{+\mathrm{i}}$ is established in $\mathrm{T}$, according to recombination, $\mathrm{Q} \rightarrow \rightarrow \mathrm{V} \cap \mathrm{P}_{\mathrm{i}}$ is also established in $\mathrm{T}$. Then, the followings will prove multi-valued dependency $\mathrm{Q} \rightarrow \rightarrow \mathrm{V} \cap \mathrm{P}_{\mathrm{i}}$ is established in $\mathrm{T}$. As to some $\mathrm{i}, \mathrm{V} \cap \mathrm{P}_{\mathrm{i}}=\quad$ or $\mathrm{V} \cap \mathrm{P}_{\mathrm{i}}=\mathrm{P}_{\mathrm{i}}$, according to Property $1, \mathrm{Q} \rightarrow \rightarrow \mathrm{P}_{\mathrm{i}}$ is established in $\mathrm{T}$, and $\mathrm{Q} \rightarrow \rightarrow$ is also established in $\mathrm{T}$; As to some $\mathrm{i}, \mathrm{V} \cap \mathrm{P}_{\mathrm{i}} \quad \mathrm{P}_{\mathrm{i}}$, if $\mathrm{Q} \cap \mathrm{P}_{\mathrm{i}}=\quad$ according to extension rules, Paths(D)- $\mathrm{P}_{\mathrm{i}} \rightarrow \rightarrow \mathrm{V}$ is established. According to Definition 10, $\mathrm{P} \rightarrow \rightarrow \mathrm{P}_{\mathrm{i}}$ is established, known from symmetry of multi-valued dependency, $\mathrm{P} \rightarrow \rightarrow$ Paths(D) $-\mathrm{P}_{\mathrm{i}}$ is established, and derived by transitivity of multi-valued dependency, $\mathrm{P} \rightarrow \rightarrow \mathrm{V}-\left(\mathrm{Paths}(\mathrm{D})-\mathrm{P}_{\mathrm{i}}\right)$ is established, further , $\mathrm{P} \rightarrow \rightarrow \mathrm{V} \cap \mathrm{P}_{\mathrm{i}}$ is established, and that is contradictory with Pi DEP(P). Therefore, the intersection of and is not empty. According to Property $2, \mathrm{Q} \rightarrow \rightarrow \mathrm{V} \cap \mathrm{P}_{\mathrm{i}}$ is established in $\mathrm{T}$ .Then as to arbitraryi $\mathrm{Q} \rightarrow \rightarrow \mathrm{V} \cap \mathrm{P}_{\mathrm{i}}$ is established, according to $\mathrm{Q} \rightarrow \mathrm{V} \rightarrow \mathrm{P}^{+}$and complement rule, $\mathrm{Q} \rightarrow \rightarrow \mathrm{V}$ is established in $\mathrm{T}$.

Last but not least, considering the dependency whose left is $\mathrm{P}$ is not in $\Sigma^{+}$. If it is a functional dependency, supposing $\mathrm{f}^{\prime}$ whose left is $\mathrm{P}$ is a function dependency not in $\Sigma^{+}$, it is formalized as $\mathrm{P} \rightarrow \mathrm{Q}$, then there is $\mathrm{Q} \mathrm{P}^{+}$, according to Definition3.10, $\mathrm{Q}$ must have intersection with some $\mathrm{P}_{\mathrm{i}}$.According to Definition1, if $\mathrm{P} \rightarrow \mathrm{Q}$ established ,then $\mathrm{P} \rightarrow \mathrm{Q} \cap \mathrm{P}_{\mathrm{i}}$ established, according to Definition $10, \mathrm{P}^{+}$and $\mathrm{P}_{\mathrm{i}}$ do not have intersection, hence, is contradictory with Property 2 . Hence, $\mathrm{P} \rightarrow \mathrm{Q}$ is not established in $\mathrm{T}$; If the dependency is multi-valued dependency, supposing $\mathrm{g}^{\prime}$ whose left is $\mathrm{P}$ is a function dependency not in $\Sigma^{+}$, it formalized as $\mathrm{P} \rightarrow \rightarrow \mathrm{Q}$, according to Definition10, $\mathrm{P} \rightarrow \mathrm{Q} \cap \mathrm{P}^{+}$and $\mathrm{P} \rightarrow \rightarrow \mathrm{Q} \cap \mathrm{P}_{\mathrm{i}}$ both established in $\mathrm{T}$, then $\mathrm{Q} \cap \mathrm{P}_{\mathrm{i}} \quad \mathrm{P}_{\mathrm{i}}$ (otherwise, since $\mathrm{Q} \rightarrow \mathrm{V} \cap \mathrm{P}^{+}$is in $\Sigma^{+}$, and as to arbitrary $\mathrm{i}$, $\mathrm{Q} \rightarrow \rightarrow \mathrm{V} \cap \mathrm{P}_{\mathrm{i}}$ is in $\Sigma^{+}$,then ,it contradictory with the assumption ).According to Property 2 , $\mathrm{P} \rightarrow \rightarrow \mathrm{Q} \cap \mathrm{P}_{\mathrm{i}}$ is not established in $\mathrm{T}$. Since $\mathrm{P} \rightarrow \rightarrow \mathrm{P}_{\mathrm{i}}$ is established in $\mathrm{T}$, if $\mathrm{P} \rightarrow \rightarrow \mathrm{Q}$ is also established in $\mathrm{T}$, known from intersection rule of XMVD, $\mathrm{P} \rightarrow \rightarrow \mathrm{Q} \cap \mathrm{P}_{\mathrm{i}}$ is established in $\mathrm{T}$ ,contradicted with the assumption. Hence, $\mathrm{P} \rightarrow \rightarrow \mathrm{Q}$ is not established in $\mathrm{T}$.

To sum up, the inference rules is complete.

\section{Conclusions}

The text, in the first place, analyzes the requirements presented by function dependency and multi-valued dependency of XML through a number of examples, proposed the formalized definition of XML function dependency and XML multi-valued dependency on this basis in detail. Then it further defined XML trivial function dependency and XML trivial multi-valued dependency. It described the definition of logical implication and coverage in the case of XML function dependency and XML multi-valued dependency coexist gave the concept of path dependency set and member set, gave inference rules set in the case of XML function dependency and multi-valued dependency coexist ,And proved the validity and completeness of the rule set.

\section{Acknowledgment}

This work has been financially supported by the Project of Major Reform to the Network Engineering Programmed in Hebei Normal University of Science and Technology, which was assigned by Hebei Education Department in 2012.

\section{References}

[1] J. J. Lu and S. Renjen, "Normalizing XML Schemas through Relational Database", //Proceedings of the 43nd Annual Southeast Regional Conference, Kennesaw, Georgia, Alabama, USA, (2005), pp. 220-221.

[2] C. Yu and H. V.Jagadish, "XML schema refinement through redundancy detection and normalization", The VLDB Journal, vol. 17, no. 2, (2008), pp. 203-223. 
[3] F. Ferrarotti, S. Hartmann and H. Köhler, "The Boyce-Codd-Heath Normal Form for SQ", Proceedings of 18th International Workshop on Logic, Language, Information and Computation, Philadelphia, PA, USA, (2011), pp. 110-122.

[4] F. Ferrarotti, S. Hartmann and H. Köhler, "Foundations for a Fourth Normal Form over SQL-Like Databases", Conceptual Modeling and Its Theoretical Foundations. Essays Dedicated to Bernhard Thalheim on the Occasion of His $60^{\text {th }}$ Birthday. London, USA, (2012), pp. 85-100.

[5] Md. S. Shahriar and J. Liu, "Towards the Preservation of Keys in XML Data Transformation for Integration", Proceedings of the 14th International Conference on Management of Data, IIT Bombay, Mumbai, India, (2008), pp. 116-126.

[6] F. Ferrarotti, S. Hartmann and S. Link, "Performance Analysis of Algorithms to Reason about XML Keys", Proceedings of 23rd International, Conference of Database and Expert Systems Applications, Vienna, Austria, (2012), pp. 101-115.

[7] G. Li, B. C. Ooi, J. Feng, J. Wang and L. Zhou, "EASE: An Effective 3-in-1 Keyword Search Method for Unstructured, Semi-structured and Structured Data", Proceedings of the ACM SIGMOD international conference on Management of data ,SIGMOD 2008, Vancouver, BC, Canada, (2008), pp. 903-914.

[8] R. Cyganiak and D. Wood, "RDF 1.1 Concepts and Abstract Syntax [EB/OL]", (2011-08-30)[2012-1015].http://www.w3.org/TR/2011/WD-rdf11-concepts-20110830.

[9] F. Ferrarotti, S. Hartmann and S. Link, "A Precious Class of Cardinality Constraints for Flexible XML Data Processing”, Proceedings of 30thInternational Conference on Conceptual Modeling, Brussels, Belgium, (2011), pp. 175-188.

[10] M. W. Vincent, J. Liu and M. Mohania, "The implication problem for 'closest node' functional dependencies incomplete XML documents", Journal of Computer and System Sciences, vol. 78, no. 4, (2012), pp. 1045-1098.

[11] J. Liu, J. Li, C. Liu and Y. Chen, "Discover Dependencies from Data-A Review”, IEEE Transactions on Knowledge and Data Engineering, vol. 24, no. 2, (2012), pp. 251-264.

[12] S. Hartmann, S. Link and T. Trinh, "Solving the Implication Problem for XML Functional Dependencies with Properties", Proceedings of the 28th international Workshop on Logic, Language, information and Computation, Brasilia, Brazil, (2010), pp. 161-175. 
International Journal of Database Theory and Application Vol.8, No.6 (2015) 